Relations industrielles

Industrial Relations

\title{
La Doctrine sociale de l'Eglise, Mgr Guerry, 1 vol., 191 pp. Bonne Presse, Paris, 1957.
}

\section{Gérard Dion}

Volume 13, numéro 1, janvier 1958

URI : https://id.erudit.org/iderudit/1022480ar

DOI : https://doi.org/10.7202/1022480ar

Aller au sommaire du numéro

Éditeur(s)

Département des relations industrielles de l’Université Laval

ISSN

0034-379X (imprimé)

1703-8138 (numérique)

Découvrir la revue

Citer ce compte rendu

Dion, G. (1958). Compte rendu de [La Doctrine sociale de l'Eglise, Mgr Guerry, 1 vol., 191 pp. Bonne Presse, Paris, 1957.] Relations industrielles / Industrial Relations, 13(1), 111-111. https://doi.org/10.7202/1022480ar

Tous droits réservés @ C Département des relations industrielles de l’Université Laval, 1958
Ce document est protégé par la loi sur le droit d'auteur. L’utilisation des services d'Érudit (y compris la reproduction) est assujettie à sa politique d'utilisation que vous pouvez consulter en ligne.

https://apropos.erudit.org/fr/usagers/politique-dutilisation/ 
L'étude du professeur Jamieson est d'une lecture facile. Elle a le mérite de condenser dans un nombre restreint de pages les éléments essentiels à la compréhension du mouvement ouvrier canadien. Il s'est glissé, ici et là, quelques erreurs de détail; certaines hypothèses mériteraient d'être approfondies davantage. Mais dans l'ensemble le lecteur y trouvera sûrement le meilleur essai de synthèse publié à date sur un sujet très complexe, le mouvement ouvrier canadien. L'auteur l'a bien situé dans son contexte géographique, social, économique, juridique et politique.

\section{GÉrard Dion}

\section{Mgr Guerry, La Doctrine sociale de} l'Eglise, 1 vol., 191 pp. Bonne Presse. Paris, 1957.

Les ouvrages sur la doctrine sociale de l'Eglise ne manquent pas. Plusieurs ont vu le jour en ces dernières années. Certains ont des qualités incontestées. Tels ceux du R.P. Vilain, s.j., et du R.P. Van Gester, o.p. D'autres pour diverses raisons sont moins recommandables.

Voici qu'un évêque français, bien connu en notre milieu pour ses travaux sur l'Action catholique, vient de publier en un petit volume une lettre pastorale au clergé et aux militants de son diocèse intitulée La Doctrine sociale de l'Eglise, son actualité, ses dimensions. son rayonnement.

Cet ouvrage est un des meilleurs que nous connaissons. On n'y trouve pas de «vasage », ni de jérémiades, ni de sentimentalisme. Son grand mérite est d'exprimer l'essentiel avec précision et concision. Grâce à des définitions claires et à des distinctions lumineuses, il dissipe les confusions entretenues par ceux qui, malgré leurs bonnes intentions, n'ont pas renouvelé leur vocabulaire ni assimilé les développements de l'enseignement social de l'Eglise depuis vingtcinq ans. L'auteur ne nous écrase pas non plus sous des montagnes de citations pour mieux cacher sa pensée, bien qu'il donne toujours en note les références les plus importantes.

L'ouvrage comprend d'abord une substantielle introduction où est dit en quoi consiste la doctrine sociale de
l'Eglise, pourquoi l'Eglise a une doctrine sociale, et où est fait réponse à un certain nombre d'objections. La première partie est consacrée à la conception de l'homme apportée au monde par cette doctrine. La seconde a trait à la conception de l'économie sociale. Mgr Guerry se propose de compléter son étude dans une autre étude où il exposera la conception chrétienne de la communauté humaine.

Cet ouvrage se recommande sans réserve à cause de l'autorité de son auteur et surtout à cause de ses qualités intrinsèques. Il peut fort bien être utilisé comme manuel pour un cours sur la doctrine sociale de l'Eglise. On le distribue aux Presses Universitaires Laval, Québec.

GÉrard Dion

Code du travail - Labor Code, par Gérard Picard, Montréal 1957. 1 volume bilingue, 245 pp.

Le président général de la CTCC vient de publier sous ce titre un essai de codification de la législation du travail pour la province de Québec. Il y exprime sa propre conception de la législation du travail ainsi que ce qu'elle doit, selon lui, comprendre. Il le fait en tenant compte des mesures législatives existantes et surtout des pratiques courantes en notre pays et de sa longue expérience dans lorganisation syndicale et la négociation de conventions collectives. Voilà pourquoi dans son essai on trouvera plusieurs suggestions que l'auteur croit devoir offrir. Comme il serait trop long de faire une étude critique de chacune des innovations, il vaut mieux se contenter de les présenter aux lecteurs, quitte à revenir plus tard sur l'une ou l'autre des originalités de ce projet. Les voici.

Le Code du Travail érige la législation du travail en un système juridique particulier et remplace les lois éparses et fragmentaires édictées depuis environ un demi-siècle.

Le Code du Travail prévoit qu'il doit y avoir consultation officielle des associations patronales et des organisations syndicales de travailleurs avant la formation de tout organisme consultatif, administratif ou semi-judiciaire relevant de la juridiction du Ministre du Travail. 